\section{Chemically transmitting synapes}

Synapses. Edited by Glen A. Cottrell and Peter N. R. Usherwood. Pp. xviii +385 . (Blackie: Glasgow, 1977.) $£ 13.95$.

THERE is a neatness and economy about the structure and function of chemically transmitting synapses that has given them an unfailing appeal for experimenters. The action potential, a brief all-or-nothing event, invades the presynaptic nerve terminal; the transmitter, synthesised and packaged on the spot, is released in quantal, countable packets; it combines with specific postsynaptic receptor sites which (in some situations at least) act to open or close discrete ionic channels in the membrane; the transmitter is then either metabolised on the spot by an enzyme appropriately lodged in the synaptic cleft, or it is taken back up by the presynaptic nerve for re-use. The whole thing seems to have an almost Toytown quality.

To the extent that good science consists in reducing the confusion of a half-understood mechanism to a series of discrete steps, this quality of our present understanding of synaptic function is a testimony to the excellence of past work in this field, and the casual observer might think that there was little left to be discovered. He would be wrong, of course, and this book, which is made up of a series of papers presented at a symposium in March 1976 , highlights very usefully just those areas where mysteries still abound; in doing so, it obviously has to take for granted a great deal, and should be read as an introduction to the growing points and vague edges of the subject rather than as a coherent resumé of the present state of knowledge.

Among many interesting papers is a series of contributions about the vesicle hypothesis, written mainly by sceptics, and these constitute a very valuable source of information for students of this tangled controversy. It is a pity, perhaps, that papers by some of the ardent defenders of the vesicle hypothesis, such as Whittaker or Heuser, were not included.

Another fascinating theme that runs through several excellent papers in this volume is that of the formation and stabilisation of synapses, which is approached through studies on the synthesis and degradation of receptors (an elegant contribution by Fambrough and his colleagues), the regeneration of synaptic connections after sectioning nerve bundles in the leech nervous system (Nicholls et al.), and studies on muscle denervation (Guttmann). This is surely one of the most challenging problems in neurobiology, and when we consider how badly understood is the mechanism even of the muchstudied effect of denervation on the distribution of receptors in skeletal muscle fibres, it is obvious that the exploration has barely begun. The Toy-town image of the finished article seems a long way away when one is faced with the problem of how the synapse develops and regenerates.

Inevitably, in a published symposium, there are inconsistencies of style and quality. Overall, though, a very high standard is achieved, and the editors are to be commended for their choice of authors. Whether much purpose is served by including 40 pages of brief abstracts as an appendix to the main part of the book is doubtful, but this is a small criticism of an otherwise excellent book.

H. P. Rang

H. P. Rang is Professor of Pharmacology at St George's Hospital Medical School, London, UK.

\section{Laboratory handbook on lysosomes}

Lysosomes: A Laboratory Handbook. Second edition. Edited by J. T. Dingle. Pp. xiv +323 (North-Holland: Amsterdam, New York, and Oxford, 1977.) Dfl. $136.00 ; \$ 55.50$.

Or: all the articles in the multi-volume Lysosomes in Biology and Pathology, edited by Dingle and his colleagues, those on techniques have been most frequently consulted. Dingle therefore decided to edit a laboratory handbook on lysosomes, which has proved sufficiently popular to justify a second edition.

The most useful chapter is a scholarly account of the properties of lysosomal enzymes by A. J. Barrett and M. F. Heath. This has been brought up to date with methods of assay and much background information. The chapter on isolation of lysosomes (R. T. Dean) follows for the most part traditional lines, using loading of rat liver with Triton, dextran, iron or gold. Methods for isolation of lysosomes from single cell types, such as leucocytes and tumour cells, are also given.
L. B. Bitensky and J. Chayen describe the histochemical identification of lysosomes at the light microscopical level, and rely on microdensitometry for quantitative results. The identification of lysosomes at the electron microscopic level is discussed by J. M. P. Schellens and his colleagues. Attractive results are obtained in various cell types by techniques for carbohydrates such as silver proteinate. Even reactions for enzymes such as acid phosphatase or $\beta$-glucuronidase can be misleading. Observations must therefore be approached with caution.

During the past five years, specific antibodies to individual lysosomal enzymes have been studied by $A$. $R$. Poole and others to monitor purity of isolated enzymes, inhibit their activity in cell's and tissues and localise individual enzymes within cells.

In general, this is a fairly comprehensive account of recent techniques for lysosomes and their constituents, well illustrated and produced. It will be as welcome and widely used as the first edition.

\section{A. C. Allison}

A. C. Allison is Head of the Division of Cell Pathology at the MRC Clinical Research Centre, Harrow, UK.

\section{BOOKS ON PURE AND APPLIED SCIENCE}

Books reviewed or mentioned in this journal are available from stock.

Catalogues on application.

Please state interests.

\section{SCIENTIFIC LIBRARY}

ANNUAL SUBSCRIPTION from $£ 7.00$

Reduced rates for multiple subscriptions Available in U.K. only

Prospectus free on request

H. K. LEWIS \& Co. Ltd.

LONDON: 136 GOWER STREET, WC1E 6BS

Telephone: $01-3874282$ 